\title{
Assessment of dexrazoxane as a cardioprotectant in doxorubicin-treated children with high-risk acute lymphoblastic leukaemia: long-term follow-up of a prospective, randomised, multicentre trial
}

Prof. Steven E Lipshultz, MD, Rebecca E Scully, BA, Stuart R Lipsitz, ScD, Prof. Stephen E Sallan, MD, Lewis B Silverman, MD, Prof. Tracie L Miller, MD, Elly V Barry, MD, Barbara L Asselin, Uma Athale, MD, Luis A Clavell, MD, Eric Larsen, MD, Albert Moghrabi, MD, Yvan Samson, MD, Bruno Michon, MD, Prof. Marshall A Schorin, MD, Prof. Harvey J Cohen, MD, Donna S Neuberg, ScD, E John Orav, PhD, and Prof. Steven D Colan, MD

University of Miami Leonard M Miller School of Medicine, Miami, FL, USA (Prof S E Lipshultz MD, R E Scully BA, Prof T L Miller MD); Holtz Children's Hospital, University of Miami/Jackson Memorial Medical Center, Miami, FL, USA (Prof S E Lipshultz, R E Scully, Prof T L Miller); and University of Miami Sylvester Comprehensive Cancer Center, Miami, FL, USA (Prof S E Lipshultz, R E Scully, Prof T L Miller); Brigham and Women's Hospital, Boston, MA, USA (S R Lipsitz ScD, E J Orav PhD); Dana-Farber Cancer Institute, Boston, MA, USA (Prof S E Sallan MD, L B Silverman MD, D S Neuberg ScD); Genzyme Corporation, Cambridge, MA, USA (E V Barry MD); University of Rochester School of Medicine and Dentistry, Rochester, NY, USA (B L Asselin MD); McMaster University, Hamilton, ON, Canada (U Athale MD); San Jorge Children's Hospital, San Juan, Puerto Rico (L A Clavell MD); Maine Children's Cancer Program, Portland, ME, USA (E Larsen MD); Sainte-Justine Hospital, Montreal, QC, Canada (A Moghrabi MD); Centre Hospitalier Universitaire de Quebec, Quebec City, QC, Canada (Y Samson MD, B Michon MD); Inova Fairfax Hospital for Children, Falls Church, VA, USA (Prof M A Schorin MD); Stanford University School of Medicine, Stanford, CA, USA (Prof H J Cohen MD); and Children's Hospital Boston, Boston, MA, USA (Prof S E Sallan, L B Silverman, Prof S D Colan MD)

\section{Summary}

\begin{abstract}
Background-Doxorubicin chemotherapy is associated with cardiomyopathy. Dexrazoxane reduces cardiac damage during treatment with doxorubicin in children with acute lymphoblastic leukaemia (ALL). We aimed to establish the long-term effect of dexrazoxane on the subclinical state of cardiac health in survivors of childhood high-risk ALL 5 years after completion of doxorubicin treatment.
\end{abstract}

Correspondence to: Prof Steven E Lipshultz, Department of Pediatrics (D820), Leonard M Miller School of Medicine, University of Miami, PO Box 016820, Miami, FL 33101, USA slipshultz@med.miami.edu.

Contributors

SEL, SES, LBS, TLM, and EJO were responsible for the concept and design of the study. SEL, RES, LBS, BLA, UA, LAC, EL, AM, YS, BM, and MAS provided study materials and patients. SEL, RES, UA, LAC, EL, AM, YS, BM, and MAS collected the data. All authors analysed and interpreted the data, wrote the report, and approved the final version of the report.

Conflicts of interest

SEL has received investigator-initiated grants from Pfizer, Novartis, and Roche Diagnostics to help support this study. Pfizer manufactures both doxorubicin and dexrazoxane. Novartis manufactures dexrazoxane in parts of the world outside the USA. Roche Diagnostics manufactures the immunoassay and analyser used to measure cardiac troponin $T$ in the patient's serum. LBS has received payment for consultancy work for Enzon Pharmaceuticals and ELISA Pharmaceuticals. EVB has received payment for consultancy work, and has stock or stock options, for Genzyme Corporation. All other authors declared that they have no conflicts of interest. 
Methods-Between January, 1996, and September, 2000, children with high-risk ALL were enrolled from nine centres in the USA, Canada, and Puerto Rico. Patients were assigned by block randomisation to receive ten doses of $30 \mathrm{mg} / \mathrm{m}^{2}$ doxorubicin alone or the same dose of doxorubicin preceded by $300 \mathrm{mg} / \mathrm{m}^{2}$ dexrazoxane. Treatment assignment was obtained through a telephone call to a centralised registrar to conceal allocation. Investigators were masked to treatment assignment but treating physicians and patients were not; however, investigators, physicians, and patients were masked to study serum cardiac troponin-T concentrations and echocardiographic measurements. The primary endpoints were late left ventricular structure and function abnormalities as assessed by echocardiography; analyses were done including all patients with data available after treatment completion. This trial has been completed and is registered with ClinicalTrials.gov, number NCT00165087.

Findings - 100 children were assigned to doxorubicin (66 analysed) and 105 to doxorubicin plus dexrazoxane (68 analysed). 5 years after the completion of doxorubicin chemotherapy, mean left ventricular fractional shortening and end-systolic dimension $Z$ scores were significantly worse than normal for children who received doxorubicin alone (left ventricular fractional shortening: $-0.82,95 \% \mathrm{CI}-1.31$ to -0.33 ; end-systolic dimension: $0.57,0.21-0.93)$ but not for those who also received dexrazoxane $(-0.41,-0.88$ to $0 \cdot 06 ; 0 \cdot 15,-0 \cdot 20$ to 0.51$)$. The protective effect of dexrazoxane, relative to doxorubicin alone, on left ventricular wall thickness (difference between groups: $0.47,0.46-0.48)$ and thickness-to-dimension ratio $(0.66,0.64-0.68)$ were the only statistically significant characteristics at 5 years. Subgroup analysis showed dexrazoxane protection $(\mathrm{p}=0.04)$ for left ventricular fractional shortening at 5 years in girls $(1 \cdot 17,0 \cdot 24-2 \cdot 11)$, but not in boys $(-0 \cdot 10,-0 \cdot 87$ to $0 \cdot 68)$. Similarly, subgroup analysis showed dexrazoxane protection $(\mathrm{p}=0.046)$ for the left ventricular thickness-to-dimension ratio at 5 years in girls $(1 \cdot 15$, $0.44-1.85)$, but not in boys $(0 \cdot 19,-0.42$ to $0 \cdot 81)$. With a median follow-up for recurrence and death of 8.7 years (range 1.3-12.1), event-free survival was 77\% (95\% CI 67-84) for children in the doxorubicin-alone group, and $76 \%$ (67-84) for children in the doxorubicin plus dexrazoxane group ( $\mathrm{p}=0.99)$.

Interpretation-Dexrazoxane provides long-term cardioprotection without compromising oncological efficacy in doxorubicin-treated children with high-risk ALL. Dexrazoxane exerts greater long-term cardioprotective effects in girls than in boys.

Funding - US National Institutes of Health, Children's Cardiomyopathy Foundation, University of Miami Women's Cancer Association, Lance Armstrong Foundation, Roche Diagnostics, Pfizer, and Novartis.

\section{Introduction}

With intensive, multidrug chemotherapy, the 5-year event-free survival for children with acute lymphoblastic leukaemia (ALL) is about $80 \%{ }^{1-5}$ More than 300000 survivors of childhood cancer are alive in the USA, and an estimated one in every 640 adults aged 20-39 years has survived childhood cancer. ${ }^{6,7}$ As this population ages, the progressive complications of early, intensive treatments are becoming increasingly apparent. ${ }^{8}$

Cardiovascular health is particularly compromised and worsens over time, and cardiac morbidity and mortality are significantly higher than is expected in long-term survivors of childhood cancer. ${ }^{9-19}$ Echocardiographic abnormalities, including left ventricular wall thinning and depressed left ventricular function, have been reported in survivors treated with doxorubicin during childhood. ${ }^{9-11}$ Compared with sibling controls, 30-year survivors of childhood cancer have significantly higher rates of congestive heart failure (relative risk $15 \cdot 1,95 \%$ CI $4 \cdot 8-47 \cdot 9)$, coronary artery disease $(10 \cdot 4,4 \cdot 1-25 \cdot 9)$, and stroke $(9 \cdot 3,4 \cdot 1-$ 21.2). ${ }^{12}$ The absolute excess risk of cardiac-specific death among long-term childhood cancer survivors ranges between 0.18 deaths per 1000 person-years (95\% CI 0.09-0.30) to 
$2 \cdot 0$ deaths per 10000 person-years $(1 \cdot 6-2 \cdot 7) \cdot{ }^{17,19}$ Delayed cardiotoxicity in long-term survivors of childhood cancer is shown by a standardised rate of cardiac death of 8.2 times higher than expected in 20-year survivors of childhood cancer, with an increase in the cumulative probability of cardiac death at $15-25$ years after diagnosis. ${ }^{14,15}$ Sudden death, presumed cardiovascular, is more than four times higher than expected. ${ }^{15}$ Delayed cardiotoxicity in cancer survivors is an increasing cause of heart transplantation. ${ }^{18,20}$

Doxorubicin, an effective anthracycline antineoplastic agent, has been associated with both early and delayed cardiomyopathy. ${ }^{9-13,16-18,20-24}$ Delayed doxorubicin-related cardiomyopathy is associated with female sex, doxorubicin exposure at a young age, long length of follow-up after treatment with doxorubicin, high individual rate of doxorubicin dose, and high cumulative doxorubicin doses. ${ }^{9-13,16-18,20-24}$ Anthracyclines are widely used in children with cancer; more than $50 \%$ of childhood cancer survivors in the USA have been treated with anthracyclines. ${ }^{25}$ The mechanism of doxorubicin's early cardiotoxic effects is partly related to free radical injury: the drug forms complexes with iron, contributing to the formation of reactive oxygen species and leading to intracellular damage and cardiomyocyte death. ${ }^{18,20-24}$ Mitochondrial DNA mutations have been implicated as a possible mechanism of delayed doxorubicin-induced cardiotoxicity in long-term survivors, but the causes are multifactorial. ${ }^{26,27}$ These pathways seem to be distinct from doxorubicin's main anticancer mechanism of DNA topoisomerase type II inhibition. ${ }^{21-24}$ Exposure to high doses of anthracycline in childhood is associated with cardiovascular morbidity and mortality; ${ }^{16,17}$ findings of one study showed a 3.1 times greater risk of cardiac death in 30-year survivors than is expected. ${ }^{13}$

Treatment with enalapril, ${ }^{28}$ growth hormone,${ }^{29}$ or continuous instead of bolus doxorubicin infusion ${ }^{30}$ does not prevent progressive cardiotoxicity in anthracycline-treated long-term survivors of childhood cancer. Therefore, at a time when anthracycline dose escalation is a useful treatment for leukaemia in adults, ${ }^{31}$ validation of a cardioprotectant against anthracyclines is important.

Dexrazoxane, an iron chelator, reduces early myocardial injury during doxorubicin treatment, as measured by increased serum cardiac troponin-T concentrations in children with ALL. ${ }^{32}$ However, whether this reduction in early myocardial damage translates to longterm improvements in cardiac health is not known. ${ }^{18,20-24,33-35}$ In preclinical models, dexrazoxane prevents doxorubicin-induced long-term cardiotoxicity, ${ }^{24}$ protects myocardial mitochondria from genetic and functional lesions, ${ }^{26}$ reduces apoptosis, ${ }^{36}$ and decreases metabolic remodelling. ${ }^{37} \mathrm{We}$ aimed to establish the effect of dexrazoxane on echocardiographic measurements in survivors of high-risk childhood ALL, 5 years after completion of doxorubicin treatment.

\section{Methods}

\section{Patients}

This study was part of the Dana-Farber Cancer Institute Childhood ALL Consortium Protocol 95-01, a multicentre clinical trial for children younger than 18 years with newly diagnosed ALL (excluding mature B-cell leukaemia); the design has been described previously. ${ }^{1}$ Briefly, children with newly diagnosed ALL from nine centres in the USA, Canada, and Puerto Rico were enrolled between January, 1996, and September, 2000. The institutional review board of each participating institution approved the study, and written informed consent was obtained from all participants or their parents or guardians before the start of treatment. 
At diagnosis, ALL was classified as standard or high risk. Children were diagnosed with high-risk ALL if they met any of the following criteria: younger than 12 months or older than 10 years and younger than 18 years, leucocyte count of 50000 cells or more per $\mu \mathrm{L}, \mathrm{T}$ cell phenotype, presence of an anterior mediastinal mass, or presence of any lymphoblasts in a sample of cerebrospinal fluid. Standard-risk patients received a low cumulative dose of doxorubicin and were not thought to be at as great a risk for late cardiac effects during the period of follow-up in this study, so only high-risk patients were eligible for inclusion in the study.

\section{Randomisation and masking}

Computer-generated randomisation assignments were prepared by the study statistician using a permuted blocks algorithm with institutional balancing to assure that a treatment imbalance within an institution was no greater than three patients. Treatment assignment was obtained through a telephone call by the treating physician or study personnel at participating sites to a centralised registrar at the Dana-Farber Cancer Institute to conceal allocation.

Children with high-risk ALL were randomly assigned to receive doxorubicin alone or doxorubicin plus dexrazoxane. Central investigators assessing serum cardiac troponin-T concentrations, echocardiographic measurements, and study results were masked throughout the study. Patients and treating physicians could not be masked to treatment assignment because of the nature of the allocated treatment, but they remained masked to centrally measured cardiac troponin-T concentrations and echocardiographic values.

\section{Procedures}

All patients received two doses of $30 \mathrm{mg} / \mathrm{m}^{2}$ doxorubicin during remission induction, and eight further $30 \mathrm{mg} / \mathrm{m}^{2}$ doses every 3 weeks during intensification after remission, for a cumulative doxorubicin dose of $300 \mathrm{mg} / \mathrm{m}^{2}$. Doxorubicin was given as either an intravenous push or as an intravenous bolus (up to $15 \mathrm{~min}$ ). Patients assigned to doxorubicin plus dexrazoxane also received $300 \mathrm{mg} / \mathrm{m}^{2}$ dexrazoxane as an intravenous bolus (up to $15 \mathrm{~min}$ ) immediately before each dose of doxorubicin.

Serum samples for assessment of cardiac troponin-T concentrations were obtained at diagnosis (day 0 , before treatment), daily for 1 week after the first induction dose of doxorubicin (days 2-7), before each doxorubicin dose during intensification, and 7 days after the final dose of doxorubicin. ${ }^{1,32,34}$ Serum was frozen immediately and stored at $-70^{\circ} \mathrm{C}$ until analysis. Cardiac troponin-T was assayed in a central laboratory by use of the Elecsys Troponin-T STAT Immunoassay (Roche Diagnostics, Indianapolis, IN, USA), which has sensitivity of $0.01 \mathrm{ng} / \mathrm{mL} .{ }^{32,38}$ Haemolysed samples were excluded. Values of more than $0.01 \mathrm{ng} / \mathrm{mL}$ were regarded as abnormal.

Echocardiography was recommended, but not compulsory, at baseline, when patients had received a cumulative doxorubicin dose of $300 \mathrm{mg} / \mathrm{m}^{2}$, at completion of ALL treatment, and every 2 years thereafter. Absence of data from a patient for a given period means that no echocardiograms were obtained during that period. The last patient enrolled in this study was assigned on Sept 16, 2000, allowing at least 9 years of echocardiographic monitoring before this analysis. Each assessment consisted of a two-dimensional, m-mode, and Doppler echo cardiogram and measurement of height and weight. Echocardiography was done locally and remeasured by central study staff who were masked to treatment allocation. Only echocardiograms obtained during the first complete remission before any relapse were analysed. 
The primary outcomes were abnormalities in left ventricular structure (end-diastolic dimension, end-systolic dimension, and end-diastolic thickness-to-dimension ratio) and function, as assessed by echocardiography. Left ventricular function was assessed from left ventricular fractional shortening, which is an index of the effects of heart rate, preload, afterload, and contractility on left ventricular systolic performance. Diastolic function was not assessed. The secondary outcome for the cardiac investigation was event-free survival. Event-free survival was measured from the date of diagnosis to the first event or until the date of last contact. We regarded induction failure and induction death as events at day 0 .

\section{Statistical analysis}

We estimated that 170 high-risk patients would be enrolled in the study over 4 years; that $75 \%$ of these patients would be alive without relapse at 4 years; and that $75 \%$ of these patients would be participants in the randomised comparison. With a total of 96 patients (48 per group), we would have $80 \%$ power to identify a difference in the incidence of late left ventricular abnormalities (afterload and/or contractility) from 50\% to 23\%, testing at the two-sided 0.05 significance level.

To standardise left ventricular data by age or body surface area and adjust for changes associated with growth, we expressed echocardiographic measurements in $\boldsymbol{Z}$ scores, which are the number of SDs the recorded measurement is above or below the predicted value. We calculated $\boldsymbol{Z}$ scores from the difference between left ventricular outcome values in patients and predicted values in healthy children, divided by the SD of a distribution of values in healthy children (webappendix). We calculated the predicted value for each outcome in healthy children with a regression model, $,, 10,39,40$ by use of data from 285 healthy children measured at the same centre and in the same manner as the study patients. ${ }^{39,40}$ The Pediatric Measurements Writing Group of the American Society of Echocardiography Pediatric and Congenital Heart Disease Council recommends that "when normative data are available, the measurements of cardiovascular structures should be expressed as $\boldsymbol{Z}$ scores", ${ }^{41}$ and therefore $\boldsymbol{Z}$ scores were used in this study. $\boldsymbol{Z}$ scores for left ventricular mass, left ventricular enddiastolic posterior wall thickness, and left ventricular dimensions were adjusted for body surface area, and $\boldsymbol{Z}$ scores for left ventricular fractional shortening were adjusted for age.

We did not design the study to obtain echocardiograms at predetermined fixed timepoints after treatment completion, so time between treatment completion and echocardiography during follow-up varies between patients. Therefore, we present the number of patients and the corresponding number of echocardiograms done in 20-month intervals. We attempted to capture the maximum amount of echocardiographic data for every patient by use of centrally generated reminders to study sites and other technicians.

Thus, we could not calculate the mean $\boldsymbol{Z}$ score at a fixed set of timepoints (eg, yearly). We fitted a repeated-measures linear mixed model in SAS PROC MIXED (version 9.2), in which the mean $\boldsymbol{Z}$ score was modelled as a linear, quadratic, and cubic function of time of echocardiograhy by use of all data from every patient at every timepoint. We modelled the correlation between $\boldsymbol{Z}$ scores measured at a pair of times on the same patient with an autoregressive structure. We then estimated the mean $\boldsymbol{Z}$ score at $0,1,2,3,4$, and 5 years in each treatment group from this mixed model, and we plotted the mean $\boldsymbol{Z}$ scores over time. Although the dropout rate did not differ between the treatment groups, the mixed-model approach adjusted for potential biases caused by increased frequency of outcome assessments or duration of follow-up in some children, which might have occurred in those with poor left ventricular function. Children remaining in the study did not differ on any clinical characteristic from those who left the study: the mixed model adjusted for missing follow-up data. ${ }^{42}$ 
To establish whether serum cardiac troponin-T concentrations during treatment predicted long-term left ventricular structure or function, we formed the dichotomous covariate abnormal cardiac troponin $\mathrm{T}$ during treatment (yes or no). We then fitted a mixed model (with the $\boldsymbol{Z}$ scores listed above as outcomes) with this variable as a covariate; age and sex were added to the model, because children with and without abnormal cardiac troponin $\mathrm{T}$ during treatment are not groups established by random assignment. From this mixed model, we obtained mean $\boldsymbol{Z}$ scores, adjusted for age and sex, at 5 years for children with and without abnormal cardiac troponin $\mathrm{T}$ during treatment.

Continuous variables were compared with $\boldsymbol{t}$ tests or Wilcoxon rank-sum tests. Proportions were compared with Fisher's exact test. All tests were two-tailed with a set at 0.05. Analysis of the primary and secondary endpoint was done with all patients with data available after treatment completion. All statistical analyses were done by use of SAS (version 9.2), with the exception of the Kaplan-Meier curve for event-free survival, which was created by use of $\mathrm{R}$ (version 8.0).

This trial is registered with ClinicalTrials.gov, number NCT00165087.

\section{Role of the funding source}

The funding sources had no role in the study design, data collection, data analysis, data interpretation, or writing of the report. The corresponding author had full access to all data, and had final responsibility to submit the report for publication.

\section{Results}

219 children with high-risk ALL were assessed, of whom 205 were enrolled and randomly assigned treatment (figure 1). In January, 2009, 158 children (77 in the doxorubicin group, 81 in the doxorubicin plus dexrazoxane group) were alive and in first remission. 62 patients were not eligible for inclusion in the analyses: four were ineligible or withdrew consent, seven never achieved complete remission, 17 relapsed before echocardiographic follow-up, three died while in first remission, 31 had no echocardiographic data available after diagnosis (figure 1). A further nine patients were excluded from analyses because they had no echocardiographic data available after treatment (figure 1). For the 143 children with at least one echocardiogram after diagnosis and the 134 children with at least one echocardiogram after treatment, demographic and clinical characteristics were well balanced between treatment groups (table 1), including median echocardiographic follow-up between boys and girls (data not shown). No patients had known or suspected cardiac disease or symptoms, or were taking cardiac drugs. No children had dose-limiting side-effects in either treatment group. At median follow-up for recurrence and death of 8.7 years (range 1.3$12 \cdot 1)$, event-free survival was $77 \%$ (95\% CI 67-84) in the doxorubicin group, and 76\% (6784 ) in the doxorubicin plus dexrazoxane group ( $\mathrm{p}=0.99$; figure $2 ; 23$ events in the doxorubicin alone group and 24 in the doxorubicin plus dexrazoxane group).

134 patients with at least one echocardiogram after treatment were included in the analysis of $\boldsymbol{Z}$ scores. Mean $\boldsymbol{Z}$ scores for left ventricular fractional shortening were significantly reduced in both groups at completion of doxorubicin treatment (figure $3 \mathrm{~A}$, table 2), indicating that left ventricular function was significantly worse in survivors than in ageexpected norms. At 5 years, the mean $\boldsymbol{Z}$ score for left ventricular fractional shortening for the doxorubicin plus dexrazoxane group did not differ significantly from that in healthy children, whereas the $\boldsymbol{Z}$ score for the doxorubicin group remained significantly reduced (table 2). The difference between the doxorubicin plus dexrazoxane and doxorubicin groups was not significant at 5 years $(-0.41,95 \% \mathrm{CI}-1 \cdot 07$ to $0 \cdot 26)$. However, we recorded a significant interaction between treatment and $\operatorname{sex}(\mathrm{p}=0.0391)$. Girls given dexrazoxane 
rather than doxorubicin alone had a significantly better left ventricular fractional shortening (difference between groups: $1 \cdot 17,0 \cdot 24-2 \cdot 11)$ than did boys $(-0 \cdot 10,-0 \cdot 87$ to $0 \cdot 68$; table 2 , figures $4 \mathrm{~A}$ and $4 \mathrm{~B}$ ). Additionally, in the doxorubicin group, the reduction in left ventricular fractional shortening was significantly greater in girls than in boys across the 5-year period (table 2, figures 4A and 4B), and the protective effect of dexrazoxane was seen predominantly in girls.

In the doxorubicin group, the mean $\boldsymbol{Z}$ score for left ventricular end-diastolic dimension was almost the same as in healthy children throughout follow-up. In the doxorubicin plus dexrazoxane group, the mean $\boldsymbol{Z}$ score was significantly lower than zero up to 3 years after treatment completion, but the difference was not significant thereafter (table 2, figure 3B). The between-group comparison showed a significant difference during the first 2 years after treatment completion but not thereafter. The $\boldsymbol{Z}$ score for girls, but not for boys, differed significantly between groups at 1 year after treatment completion but converged with longer follow-up (data not shown).

Throughout follow-up, the mean $\boldsymbol{Z}$ score for left ventricular end-systolic dimension was close to zero in the doxorubicin plus dexrazoxane group, but was significantly greater than zero in the doxorubicin group (table 2, figure $3 \mathrm{C}$ ). The results were similar when the data for boys and girls were analysed separately, although the $\boldsymbol{Z}$ scores for girls differed significantly between treatment groups during the first 3 years after treatment completion (data not shown).

The mean $\boldsymbol{Z}$ score for left ventricular end-diastolic thickness-to-dimension ratio was close to zero for most of follow-up in the doxorubicin plus dexrazoxane group, but reduced significantly compared with zero at 5 years (table 2, figure 3D). However, in the doxorubicin group, the score progressively reduced and was significantly lower than zero from 2 years onwards. The between-group difference was significant for years 3-5. In boys, the mean $\boldsymbol{Z}$ score was significantly less than zero from 2 years onwards in the doxorubicin plus dexrazoxane group and from 3 years onwards in the doxorubicin group, with no significant between-group difference (table 2, figure 4D). However, in girls, the mean $\boldsymbol{Z}$ score differed significantly between groups from 2 years onwards, with the score in the doxorubicin plus dexrazoxane group close to zero throughout follow-up and the score was significantly different from zero from 1 year onwards in the doxorubicin group (table 2 , figure 4C). We recorded a significant interaction between treatment and sex for this outcome $(p=0.0317)$, indicating that the effect of treatment on the left ventricular end-diastolic thickness-to-dimension ratio was significantly different in boys and girls. For example, at 5 years after treatment completion, the effect of doxorubicin plus dexrazoxane treatment in girls minus that in boys was significantly different from zero (difference $-0 \cdot 96,-1 \cdot 88$ to $-0 \cdot 016$; table 2).

5 years after treatment, mean $\boldsymbol{Z}$ scores for left ventricular mass, left ventricular end-diastolic posterior wall thickness, and left ventricular end-diastolic thickness-to-dimension ratio were significantly lower in children who had at least one raised serum cardiac troponin- $\mathrm{T}$ concentration $(>0.01 \mathrm{ng} / \mathrm{mL})$ during treatment than in those who had no raised concentrations (table 3 ).

\section{Discussion}

For children with high-risk ALL who were treated with doxorubicin, the addition of dexrazoxane had a long-term cardioprotective effect, as indicated by echocardiographic measurements of left ventricular structure and function. The cardioprotective effect of dexrazoxane was more pronounced in girls than in boys. Although dexrazoxane seemed to 
reduce long-term cardiotoxicity, it did not adversely affect relapse risk, frequency of second malignant neoplasms, or survival in children with high-risk ALL. ${ }^{1,34}$

Doxorubicin and other anthracycline drugs are active agents in treatment of childhood ALL, but their use has been limited by acute and delayed cardiac toxic effects. In clinical trials undertaken in the 1970s, before the recognition that high cumulative doses were associated with a greater risk of delayed cardiotoxicity, children with ALL received cumulative doxorubicin doses greater than $400 \mathrm{mg} / \mathrm{m}^{2}$. We and others have shown that such patients had clinically significant left ventricular effects that continued to be progressive even decades after the completion of doxorubicin treatment. ${ }^{9-11}$ On the basis of these findings, we reduced doses of doxorubicin given to children and adolescents with ALL treated in the $1980 \mathrm{~s}$, so that standard-risk patients received a low cumulative dose $\left(45-60 \mathrm{mg} / \mathrm{m}^{2}\right)$, which was associated with a much lower risk of delayed cardiotoxicity, and high-risk patients received a $345-360 \mathrm{mg} / \mathrm{m}^{2}$ cumulative doxorubicin dose. ${ }^{32,43}$ Although the frequency of overt congestive heart failure was much reduced, follow-up of patients treated in this way suggested that there was still a risk of delayed left ventricular abnormalities in the patients with high-risk ALL. ${ }^{9-11}$

In the 1990s, we compared the left ventricular results from our long-term survivors with those from patients treated in Denmark. ${ }^{44}$ This analysis suggested that the risk of left ventricular abnormalities was lower in patients who received $300 \mathrm{mg} / \mathrm{m}^{2}$ or less than it was in those who received more than $300 \mathrm{mg} / \mathrm{m}^{2}$ of doxorubicin. From these results, we lowered the cumulative doxorubicin dose for patients with high-risk ALL to $300 \mathrm{mg} / \mathrm{m}^{2}$ on protocol 95-01. To further reduce the risk of late cardiotoxicity, we assessed the potential cardioprotective effects of dexrazoxane-an agent which, at the time that this study was undertaken (1996-2000), had been shown to prevent or attenuate early cardiotoxicity in adults with advanced malignancies treated with very high cumulative doxorubicin doses ${ }^{45}$ but had not yet been studied in a multicentre randomised trial in a paediatric cancer population.

We previously reported that dexrazoxane reduced the number and the extent (maximum value per patient) of serum cardiac troponin-T elevations during treatment in this same population, ${ }^{32}$ suggesting a reduction in early heart muscle damage during therapy. ${ }^{35,46}$ The echocardiographic data reported here suggest that dexrazoxane provides long-term cardioprotection, implying that prevention of cardiomyocyte damage during therapy can also reduce delayed doxorubicin-associated cardiomyopathy in long-term survivors without compromising the chances of oncological cure.

We have previously reported that some of these same left ventricular measurements were the strongest predictors of subsequent all-cause mortality in young children in multivariable models incorporating other known causes of mortality. ${ }^{47}$ Thus, these left ventricular biomarkers were validated as surrogate markers for subsequent mortality, in some cases identifying at-risk children 3 years before an event. ${ }^{47}$ We have also shown that the change in these same left ventricular measurements over time further defines subsequent all-cause mortality in young children following the same echocardiographic protocol and central remeasurement facility used here. ${ }^{48}$ Because these left ventricular measurements have been validated as surrogate endpoints for subsequent mortality in young children in these and other studies, and since we have shown that these parameters change longitudinally over time in ways that follow cardiac outcomes in large population-based studies of clinically significant cardiac outcomes in childhood cancer survivors from the USA, UK, France, and the Nordic countries with decades of follow-up, ${ }^{14-19}$ we have used these parameters in this study, and a priori these left ventricular parameters were our primary study endpoints. ${ }^{11}$ 
On the basis of the epidemiological published work, these interim left ventricular assessments are the best we have because the clinically significant cardiovascular endpoints, when they occur, tend to be quite late. No clinical evidence of cardiovascular disease is available, but there is certainly echocardiographic evidence of subclinical left ventricular disease progression. The magnitude of the $\boldsymbol{Z}$ score differences in this study might seem to be small relative to those that guide the daily clinical decisions by cardiologists. However, their magnitude is consistent with findings in children in which the magnitude of these $\boldsymbol{Z}$ score differences independently predicted mortality. ${ }^{47,48}$

We have assessed the reliability of these left ventricular measurements in paediatric multicentre studies following a similar protocol at the same central remeasurement facility. ${ }^{49}$ The substantial improvement in reliability by use of a central remeasurement facility, relative to use of data received from measurements taken locally, has led to this central measurement facility being used in many paediatric multicentre studies.

Left ventricular function, measured by left ventricular fractional shortening, was closer to normal in the doxorubicin plus dexrazoxane group than in the doxorubicin-only group (although, overall, the treatment groups did not differ significantly from each other; they were significantly different in girls). Additionally, left ventricular end-systolic dimension and left ventricular end-diastolic posterior wall thickness were also nearer to normal in the doxorubicin plus dexrazoxane group. One explanation for these findings is the absence of left ventricular remodelling (the constellation of progressive cardiomyocyte lengthening, left ventricular wall-thinning and dilation, and reshaping of the left ventricular in response to myocardial loss or injury), ${ }^{50,51}$ as suggested by the normal left ventricular thickness-todimension ratio in children treated with dexrazoxane, especially girls. The diminished left ventricular thickness-to-dimension ratio in all boys, irrespective of randomised treatment, results in increased left ventricular wall stress, and this is the finding we have previously identified as being most characteristic of the long-term toxic effects of doxorubicin. ${ }^{9-11}$

The absence of left ventricular remodelling in dexrazoxane-treated patients might imply a more positive prognosis, in view of what is known about myocardial injury from other causes. For example, in patients with myocardial infarction, myocarditis, or idiopathic dilated cardiomyopathy, the changes in left ventricular mass, size, and shape, and the associated subcellular changes representing left ventricular remodelling, are associated with progressive heart failure and poor prognosis. ${ }^{46,47}$ Interruption of the molecular and physiological pathways that contribute to cardiomyocyte loss and the resulting unfavourable left ventricular geometry can abrogate remodelling and prevent or delay cardiomyopathy and heart failure. Remodelling has many factorial causes and involves several parallel cellular pathways, but dexrazoxane seems to be able to prevent the primary injury that leads to the doxorubicin-associated left ventricular remodelling. ${ }^{37,52}$

Dexrazoxane seemed to benefit girls more than boys. We have noted other sex differences in treatment-related toxic effects and outcomes. ${ }^{53}$ Some studies suggest that girls with ALL are more likely to have cognitive dysfunction or obesity than boys, but are less likely to relapse. ${ }^{54-57}$ Female sex is an independent risk factor for delayed doxorubicin cardiotoxicity. ${ }^{10,58}$ The reason for this finding is not fully understood, although sex-related differences in the transport and clearance of doxorubicin have been reported. ${ }^{59-61}$

Furthermore, dexrazoxane cardioprotection has been reported against the sex-related hormone testosterone. ${ }^{62}$ Differences between men and women in the causation, pathophysiology, and prognosis of heart failure have been recorded. ${ }^{63}$ Sex-related differences occur in newborn babies, with girls having greater elevations of myocardial injury-markers than boys. ${ }^{64}$ Girls have a higher risk of death during admissions for paediatric cardiac surgery than do boys. ${ }^{65}$ Exposure of antiretroviral therapy to young girls 
is also associated with more inadequate left ventricular growth than in boys, suggesting an increased sensitivity of the young female myocardium to toxic exposures. ${ }^{66}$ Our results suggest that optimum cardioprotective strategies might also vary by sex.

Echocardiographic changes were related to serum cardiac troponin- $\mathrm{T}$ concentrations measured during doxorubicin chemotherapy. These findings validate the use of serum cardiac troponin $\mathrm{T}$ as a surrogate endpoint for left ventricular status in long-term survivors of childhood high-risk ALL, as suggested by previous studies of animals receiving doxorubicin, ${ }^{35,46}$ and adult patients receiving high-dose chemotherapy,${ }^{67}$ in addition to our previous results. ${ }^{38}$ However, additional biomarkers might be necessary to improve predictive ability. ${ }^{18,22,68}$

So far, no child enrolled in this study has had symptomatic left ventricular dysfunction. Whether the effects of dexrazoxane on left ventricular structure and function recorded in this study will translate into improved cardiac outcomes, such as a reduction in heart failure, is uncertain and needs longer follow-up. ${ }^{69,70}$ Moreover, although dexrazoxane treatment seemed to result in fewer left ventricular abnormalities 5 years after therapy, some left ventricular abnormalities persisted. In a study of 115 long-term survivors of childhood ALL treated with doxorubicin followed up for a median of 11.8 years, we showed that left ventricular abnormalities increased progressively over time. ${ }^{9-11}$ Thus, even the subtle left ventricular abnormalities we recorded in dexrazoxane-treated patients could potentially become more serious.

Other investigators have been reluctant to use dexrazoxane, because of fears that it might protect the cancer cells, in addition to the cardiomyocytes. In our experience, long-term event-free survival does not differ significantly between the doxorubicin plus dexrazoxane and doxorubicin-only groups. ${ }^{1,34}$ In a series of reports of long-term follow-up of more than 4000 children treated for ALL in the USA, UK, Europe, and Japan, none of whom received dexrazoxane, the cumulative incidence of second malignant neoplasms ranged from less than $1 \%$ to $9.9 \%$, with most studies in the range of less than $1 \%$ to $2 \%{ }^{71-77}$ Moreover, we did not find the association between dexrazoxane and second malignant neoplasms ${ }^{34}$ that was reported ${ }^{78}$ although questioned, ${ }^{79,80}$ in a paediatric Hodgkin's lymphoma trial in which three DNA topoi-somerase type II inhibitors, some noted to be associated with second malignancies in childhood cancer survivors, ${ }^{81,82}$ were given together. In addition to the 100 dexrazoxane-treated patients enrolled in this randomised clinical trial, we have also treated an additional 196 children with high-risk ALL, again with dexrazoxane, in a successor protocol undertaken between 2000 and 2004 (median follow-up 4.9 years), and in a third trial of 242 additional children from 2005 to 2010 (median follow-up 2 years). We have seen only one second malignant neoplasm, and, arguably, even that one was not a true second malignant neoplasm (a late-occurring acute myelogenous leukaemia in a child originally diagnosed with mixed-lineage leukaemia $[\boldsymbol{M L} \boldsymbol{L}]$ gene-rearranged ALL; Sallan S, DanaFarber Cancer Institute, Boston, MA, USA, personal communication). Clarification of our results and those of others in terms of risk of second malignancy must await additional details and data analysis.

A potential limitation to this study is the loss to echocardiographic follow-up, which is a general drawback in all long-term follow-up studies of cured patients. Because this study had complete follow-up from an oncological perspective and echocardiographic follow-up on any patient with an event, and in combination with the balance of follow-up between groups, we feel that any potential bias is low and does not affect the validity of our results. Although our study shows that dexrazoxane reduces doxorubicin-associated cardiotoxicity without reducing oncological efficacy, another limitation is that we did not look at other 
possible cytoprotective activities ${ }^{69}$ such as reductions in nephrotoxicity, mitochondrial cardiotoxicity, neurotoxicity, and hepatotoxicity. ${ }^{26,69,83-85}$

Our findings suggest that dexrazoxane is an important component of cardioprotection without compromising oncological activity, but that the use of dexrazoxane might be insufficient to fully prevent long-term left ventricular dysfunction, at least in some groups of patients (panel). Similar long-term cardioprotective effects of dexrazoxane in children with solid tumours are also reported. ${ }^{91}$ Future studies should focus on the identification of better predictors of at-risk patients and additional preventive therapies, especially for boys, to fully optimise cardioprotection in paediatric patients who receive anthracycline chemotherapies such as doxorubicin.

\section{Acknowledgments}

This study was supported by grants from the US National Institutes of Health (HL072705, HL078522, HL053392, CA127642, CA068484, HD052104, AI50274, CA068484, HD052102, HL087708, HL079233, HL004537, HL087000, HL007188, HL094100, HL095127, and HD80002), Children's Cardiomyopathy Foundation, University of Miami Women's Cancer Association, Lance Armstrong Foundation, Roche Diagnostics, Pfizer, and Novartis. We thank Suzanne E Dahlberg for her statistical advice; and Vivian I Franco and Jacqueline M Henkel for their editorial assistance.

\section{References}

1. Moghrabi A, Levy DE, Asselin B, et al. Results of the Dana-Farber Cancer Institute ALL Consortium Protocol 95-01 for children with acute lymphoblastic leukemia. Blood. 2007; 109:896904. [PubMed: 17003366]

2. Silverman LB, Gelber RD, Dalton VK, et al. Improved outcome for children with acute lymphoblastic leukemia: results of Dana-Farber Consortium Protocol 91-01. Blood. 2001; 97:1211-18. [PubMed: 11222362]

3. Schrappe M, Reiter A, Ludwig WD, et al. Improved outcome in childhood acute lymphoblastic leukemia despite reduced use of anthracyclines and cranial radiotherapy: results of trial ALL-BFM 90. German-Austrian-Swiss ALL-BFM Study Group. Blood. 2000; 95:3310-22. [PubMed: 10828010]

4. Pui CH, Campana D, Pei D, et al. Treating childhood acute lymphoblastic leukemia without cranial irradiation. N Engl J Med. 2009; 360:2730-41. [PubMed: 19553647]

5. Gaynon PS, Trigg ME, Heerema NA, et al. Children's Cancer Group trials in childhood acute lymphoblastic leukemia: 1983-1995. Leukemia. 2000; 14:2223-33. [PubMed: 11187913]

6. Hewitt, M.; Weiner, SL.; Simone, JV. Childhood cancer survivorship: improving care and quality of life. Washington, DC: The National Academies Press; 2003. p. 1-14.

7. Jemal A, Siegel R, Ward E, et al. Cancer statistics, 2008. CA Cancer J Clin. 2008; 58:71-96. [PubMed: 18287387]

8. Geenen MM, Cardous-Ubbink MC, Kremer LC, et al. Medical assessment of adverse health outcomes in long-term survivors of childhood cancer. JAMA. 2007; 297:2705-15. [PubMed: 17595271]

9. Lipshultz SE, Colan SD, Gelber RD, Perez-Atayde AR, Sallan SE, Sanders SP. Late cardiac effects of doxorubicin therapy for acute lymphoblastic leukemia in childhood. N Engl J Med. 1991; 324:808-15. [PubMed: 1997853]

10. Lipshultz SE, Lipsitz SR, Mone SM, et al. Female sex and drug dose as risk factors for late cardiotoxic effects of doxorubicin therapy for childhood cancer. N Engl J Med. 1995; 332:1738 43. [PubMed: 7760889]

11. Lipshultz SE, Lipsitz SR, Sallan SE, et al. Chronic progressive cardiac dysfunction years after doxorubicin therapy for childhood acute lymphoblastic leukemia. J Clin Oncol. 2005; 23:2629-36. [PubMed: 15837978] 
12. Oeffinger KC, Mertens AC, Sklar CA, et al. for the Childhood Cancer Survivor Study. Chronic health conditions in adult survivors of childhood cancer. N Engl J Med. 2006; 355:1572-82. [PubMed: 17035650]

13. Armstrong GT, Liu O, Yasui Y, et al. Late mortality among 5-year survivors of childhood cancer: a summary from the Childhood Cancer Survivor Study. J Clin Oncol. 2009; 27:2328-38. [PubMed: 19332714]

14. Mertens AC, Yasui Y, Neglia JP, et al. Late mortality experience in five-year survivors of childhood and adolescent cancer: the Childhood Cancer Survivor Study. J Clin Oncol. 2001; 19:3163-72. [PubMed: 11432882]

15. Möller TR, Garwicz S, Barlow L, et al. for the Association of the Nordic Cancer Registries and the Nordic Society for Pediatric Hematology and Oncology. Decreasing late mortality among fiveyear survivors of cancer in childhood and adolescence: a population-based study in the Nordic countries. J Clin Oncol. 2001; 19:3173-81. [PubMed: 11432883]

16. Mulrooney DA, Yeazel MW, Kawashima T, et al. Cardiac outcomes in a cohort of adult survivors of childhood and adolescent cancer: retrospective analysis of the Childhood Cancer Survivor Study cohort. BMJ. 2009; 339:b4606. [PubMed: 19996459]

17. Tukenova M, Guibout C, Oberlin O, et al. Role of cancer treatment in long-term overall and cardiovascular mortality after childhood cancer. J Clin Oncol. 2010; 28:1308-15. [PubMed: 20142603]

18. Lipshultz SE, Adams MJ. Cardiotoxicity after childhood cancer: beginning with the end in mind. J Clin Oncol. 2010; 28:1276-81. [PubMed: 20142585]

19. Reulen RC, Winter DL, Frobisher C, et al. for the British Childhood Cancer Survivor Study Steering Group. Long-term cause-specific mortality among survivors of childhood cancer. JAMA. 2010; 304:172-79. [PubMed: 20628130]

20. Levitt G, Anazodo A, Burch M, Bunch K. Cardiac or cardiopulmonary transplantation in childhood cancer survivors: an increasing need? Eur J Cancer. 2009; 45:3027-34. [PubMed: 19744853]

21. Lipshultz SE, Alvarez JA, Scully RE. Anthracycline associated cardiotoxicity in survivors of childhood cancer. Heart. 2008; 94:525-33. [PubMed: 18347383]

22. Gianni L, Herman EH, Lipshultz SE, Minotti G, Sarvazyan N, Sawyer DB. Anthracycline cardiotoxicity: from bench to bedside. J Clin Oncol. 2008; 26:3777-84. [PubMed: 18669466]

23. Barry E, Alvarez JA, Scully RE, Miller TL, Lipshultz SE. Anthracycline-induced cardiotoxicity: course, pathophysiology, prevention and management. Expert Opin Pharmacother. 2007; 8:1039_ 58. [PubMed: 17516870]

24. Wouters KA, Kremer LC, Miller TL, Herman EH, Lipshultz SE. Protecting against anthracyclineinduced myocardial damage: a review of the most promising strategies. Br J Haematol. 2005; 131:561-78. [PubMed: 16351632]

25. Krischer JP, Epstein S, Cuthbertson DD, Goorin AM, Epstein ML, Lipshultz SE. Clinical cardiotoxicity following anthracycline treatment for childhood cancer: the Pediatric Oncology Group experience. J Clin Oncol. 1997; 15:1544-52. [PubMed: 9193351]

26. Lebrecht D, Geist A, Ketelsen UP, Haberstroh J, Setzer B, Walker UA. Dexrazoxane prevents doxorubicin-induced long-term cardiotoxicity and protects myocardial mitochondria from genetic and functional lesions in rats. Br J Pharmacol. 2007; 151:771-78. [PubMed: 17519947]

27. Lipshultz SE, Walker VE, Torres SM, et al. Frequent mitochondrial DNA mutations and polymorphisms in long-term survivors of childhood acute lymphoblastic leukemia. Blood. 2007; 118:824A (abstr).

28. Lipshultz SE, Lipsitz SR, Sallan SE, et al. Long-term enalapril therapy for left ventricular dysfunction in doxorubicin-treated survivors of childhood cancer. J Clin Oncol. 2002; 20:4517-22. [PubMed: 12454107]

29. Lipshultz SE, Vlach SA, Lipsitz SR, Sallan SE, Schwartz ML, Colan SD. Cardiac changes associated with growth hormone therapy in children treated with anthracyclines. Pediatrics. 2005; 115:1613-22. [PubMed: 15930224] 
30. Lipshultz SE, Giantris AL, Lipsitz SR, et al. Doxorubicin administration by continuous infusion is not cardioprotective: the Dana-Farber 91-01 Acute Lymphoblastic Leukemia protocol. J Clin Oncol. 2002; 20:1677-82. [PubMed: 11896119]

31. Fernandez HF, Sun Z, Yao X, et al. Anthracycline dose intensification in acute myeloid leukemia. N Engl J Med. 2009; 361:1249-59. [PubMed: 19776406]

32. Lipshultz SE, Rifai N, Dalton VM, et al. The effect of dexrazoxane on myocardial injury in doxorubicin-treated children with acute lymphoblastic leukemia. N Engl J Med. 2004; 351:14553. [PubMed: 15247354]

33. Lipshultz SE. Dexrazoxane for protection against cardiotoxic effects of anthracyclines in children. J Clin Oncol. 1996; 14:328-31. [PubMed: 8636739]

34. Barry EV, Vrooman LM, Dahlberg SE, et al. Absence of secondary malignant neoplasms in children with high-risk acute lymphoblastic leukemia treated with dexrazoxane. J Clin Oncol. 2008; 26:1106-11. [PubMed: 18309945]

35. Herman EH, Zhang J, Rifai N, et al. The use of serum levels of cardiac troponin $\mathrm{T}$ to compare the protective activity of dexrazoxane against doxorubicin- and mitoxantrone-induced cardiotoxicity. Cancer Chemother Pharmacol. 2001; 48:297-304. [PubMed: 11710630]

36. Popelová O, Sterba M, Hasková P, et al. Dexrazoxane-afforded protection against chronic anthracycline cardiotoxicity in vivo: effective rescue of cardiomyocytes from apoptotic cell death. Br J Cancer. 2009; 101:792-802. [PubMed: 19623174]

37. Carvalho RA, Sousa RP, Cadete VJ, et al. Metabolic remodeling associated with subchronic doxorubicin cardiomyopathy. Toxicology. 2010; 270:92-98. [PubMed: 20132857]

38. Lipshultz SE, Rifai N, Sallan SE, et al. Predictive value of cardiac troponin T in pediatric patients at risk for myocardial injury. Circulation. 1997; 96:2641-48. [PubMed: 9355905]

39. Colan SD, Parness IA, Spevak PJ, Sanders SP. Developmental modulation of myocardial mechanics: age- and growth-related alterations in afterload and contractility. J Am Coll Cardiol. 1992; 19:619-629. [PubMed: 1538019]

40. Sluysmans T, Colan SD. Theoretical and empirical derivation of cardiovascular allometric relationships in children. J Appl Physiol. 2005; 99:445-57. [PubMed: 15557009]

41. Lopez L, Colan SD, Frommelt PC, et al. Recommendations for quantification methods during the performance of a pediatric echocardiogram: a report from the Pediatric Measurements Writing Group of the American Society of Echocardiography Pediatric and Congenital Heart Disease Council. J Am Soc Echocardiogr. 2010; 23:465-95. [PubMed: 20451803]

42. Lipsitz SR, Fitzmaurice GM, Ibrahim JG, Gelber R, Lipshultz S. Parameter estimation in longitudinal studies with outcome-dependent follow-up. Biometrics. 2002; 58:621-30. [PubMed: 12229997]

43. Schorin MA, Blattner S, Gelber RD, et al. Treatment of childhood acute lymphoblastic leukemia: results of Dana-Farber Cancer Institute/Children's Hospital Acute Lymphoblastic Leukemia Consortium Protocol 85-01. J Clin Oncol. 1994; 12:740-47. [PubMed: 8151317]

44. Nysom K, Holm K, Lipsitz SR, et al. Relationship between cumulative anthracycline dose and late cardiotoxicity in childhood acute lymphoblastic leukemia. J Clin Oncol. 1998; 16:545-50. [PubMed: 9469339]

45. Marty M, Espié M, Llombart A, et al. for the Dexrazoxane Study Group. Multicenter randomized phase III study of the cardioprotective effect of dexrazoxane (Cardioxane) in advanced/metastatic breast cancer patients treated with anthracycline-based chemotherapy. Ann Oncol. 2006; 17:61422. [PubMed: 16423847]

46. Herman EH, Zhang J, Lipshultz SE, et al. Correlation between serum levels of cardiac troponin-T and the severity of the chronic cardiomyopathy induced by doxorubicin. J Clin Oncol. 1999; 17:2237-43. [PubMed: 10561281]

47. Lipshultz SE, Easley KA, Orav EJ, et al. Cardiac dysfunction and mortality in HIV-infected children. The prospective $\mathrm{P}^{2} \mathrm{C}^{2} \mathrm{HIV}$ multicenter study. Pediatric Pulmonary and Cardiac Complications of Vertically Transmitted HIV Infection $\left(\mathrm{P}^{2} \mathrm{C}^{2} \mathrm{HIV}\right)$ Study Group. Circulation. 2000; 102:1542-48. [PubMed: 11182983]

48. Fisher SD, Easley KA, Orav EJ, et al. for the Pediatric Pulmonary and Cardiac Complications of Vertically Transmitted HIV Infection $\left(\mathrm{P}^{2} \mathrm{C}^{2} \mathrm{HIV}\right)$ Study Group. Mild dilated cardiomyopathy and 
increased left ventricular mass predict mortality: the prospective $\mathrm{P}^{2} \mathrm{C}^{2} \mathrm{HIV}$ Multicenter study. Am Heart J. 2005; 150:439-47. [PubMed: 16169321]

49. Lipshultz SE, Easley K, Orav EJ, et al. The reliability of multicenter pediatric echocardiographic measurements of left ventricular structure and function: the prospective $\mathrm{P}^{2} \mathrm{C}^{2} \mathrm{HIV}$ study. Circulation. 2001; 104:310-16. [PubMed: 11457750]

50. Pfeffer MA, Braunwald E. Ventricular remodeling after myocardial infarction. Experimental observations and clinical implications. Circulation. 1990; 81:1161-72. [PubMed: 2138525]

51. Cohn JN, Ferrari R, Sharpe N. on behalf of an International Forum on Cardic Remodeling. Cardiac remodeling-concepts and clinical implications: a consensus paper from an international forum on cardiac remodeling. J Am Coll Cardiol. 2000; 35:569-82. [PubMed: 10716457]

52. Adamcová M, Potá3ová A, Popelová O, et al. Cardiac remodeling and MMPs on the model of chronic daunorubicin-induced cardiomyopathy in rabbits. Physiol Res. 2010 published online April 20.

53. Miller TL, Lipsitz SR, Lopez-Mitnik G, et al. Characteristics and determinants of adiposity in pediatric cancer survivors. Cancer Epidemiol Biomarkers Prev. 2010; 19:2013-22. [PubMed: 20647396]

54. Armstrong GT, Sklar CA, Hudson MM, Robison LL. Long-term health status among survivors of childhood cancer: does sex matter? J Clin Oncol. 2007; 25:4477-89. [PubMed: 17906209]

55. Pui CH, Boyett JM, Relling MV, et al. Sex differences in prognosis for children with acute lymphoblastic leukemia. J Clin Oncol. 1999; 17:818-24. [PubMed: 10071272]

56. Waber DP, Tarbell NJ, Kahn CM, Gelber RD, Sallan SE. The relationship of sex and treatment modality to neuropsychologic outcome in childhood acute lymphoblastic leukemia. J Clin Oncol. 1992; 10:810-17. [PubMed: 1569453]

57. Oeffinger KC, Mertens AC, Sklar CA, et al. for the Childhood Cancer Survivor Study. Obesity in adult survivors of childhood acute lymphoblastic leukemia: a report from the Childhood Cancer Survivor Study. J Clin Oncol. 2003; 21:1359-65. [PubMed: 12663727]

58. Silber JH, Jakacki RI, Larsen RL, Goldwein JW, Barber G. Increased risk of cardiac dysfunction after anthracyclines in girls. Med Pediatr Oncol. 1993; 21:477-79. [PubMed: 8341214]

59. Thompson PA, Rosner GL, Matthay KK, et al. Impact of body composition on pharmacokinetics of doxorubicin in children: a Glaser Pediatric Research Network study. Cancer Chemother Pharmacol. 2009; 64:243-51. [PubMed: 19020877]

60. Sparreboom A, Wolff AC, Mathijssen RH, et al. Evaluation of alternate size descriptors for dose calculation of anticancer drugs in the obese. J Clin Oncol. 2007; 25:4707-13. [PubMed: 17947717]

61. Schuetz EG, Furuya KN, Schuetz JD. Interindividual variation in expression of P-glycoprotein in normal human liver and secondary hepatic neoplasms. J Pharmacol Exp Ther. 1995; 275:1011-18. [PubMed: 7473127]

62. Belhani D, Fanton L, Vaillant F, et al. Cardiac lesions induced by testosterone: protective effects of dexrazoxane and trimetazindine. Cardiovasc Toxicol. 2009; 9:64-69. [PubMed: 19484391]

63. Hsoch EM, Piña IL. Heart failure in women: a need for prospective data. J Am Coll Cardiol. 2009; 54:491-98. [PubMed: 19643307]

64. Lipshultz SE, Simbre VC 2nd, Hart S, et al. Frequency of elevations in markers of cardiomyocyte damage in otherwise healthy newborns. Am J Cardiol. 2008; 102:761-66. [PubMed: 18774003]

65. Seifert HA, Howard DL, Silber JH, Jobes DR. Female gender increases the risk of death during hospitalization for pediatric cardiac surgery. J Thorac Cardiovasc Surg. 2007; 133:668-75. [PubMed: 17320563]

66. Lipshultz SE, Shearer WT, Thompson B, et al. Cardiac effects of antiretroviral therapy in HIVnegative infants born to HIV-positive mothers: the NHLBI CHAART-1 cohort study. J Am Coll Cardiol. (in press).

67. Cardinale D, Sandri MT, Colombo A, et al. Prognostic value of troponin I in cardiac risk stratification of cancer patients undergoing high-dose chemotherapy. Circulation. 2004; 109:274954. [PubMed: 15148277]

68. Lipshultz SE, Wilkinson JD, Messiah SE, Miller TL. Clinical research directions in pediatric cardiology. Curr Opin Pediatr. 2009; 21:585-93. [PubMed: 19584723] 
69. Jones RL. Utility of dexrazoxane for the reduction of anthracycline-induced cardiotoxicity. Expert Rev Cardiovasc Ther. 2008; 6:1311-17. [PubMed: 19018683]

70. van Dalen EC, Caron HN, Dickinson HO, Kremer LC. Cardioprotective interventions for cancer patients receiving anthracyclines. Cochrane Database Syst Rev. 2008; 2:CD003917. [PubMed: 18425895]

71. Gaynon PS, Angiolillo AL, Carroll WL, et al. for the Children's Oncology Group. Long-term results of the children's cancer group studies for childhood acute lymphoblastic leukemia 19832002: a Children's Oncology Group Report. Leukemia. 2010; 24:285-97. [PubMed: 20016531]

72. Pui CH, Pei D, Sandlund JT, et al. Long-term results of St Jude Total Therapy Studies 11, 12, 13A, 13B, and 14 for childhood acute lymphoblastic leukemia. Leukemia. 2010; 24:371-82. [PubMed: 20010620]

73. Mitchell C, Richards S, Harrison CJ, Eden T. Long-term follow-up of the United Kingdom medical research council protocols for childhood acute lymphoblastic leukaemia, 1980-2001. Leukemia. 2010; 24:406-18. [PubMed: 20010621]

74. Conter V, Aricò M, Basso G, et al. Long-term results of the Italian Association of Pediatric Hematology and Oncology (AIEOP) Studies 82, 87, 88, 91 and 95 for childhood acute lymphoblastic leukemia. Leukemia. 2010; 24:255-64. [PubMed: 20016536]

75. Möricke A, Zimmermann M, Reiter A, et al. Long-term results of five consecutive trials in childhood acute lymphoblastic leukemia performed by the ALL-BFM study group from 1981 to 2000. Leukemia. 2010; 24:265-84. [PubMed: 20010625]

76. Kamps WA, van der Pal-de Bruin KM, Veerman AJ, Fiocco M, Bierings M, Pieters R. Long-term results of Dutch Childhood Oncology Group studies for children with acute lymphoblastic leukemia from 1984 to 2004. Leukemia. 2010; 24:309-19. [PubMed: 20016528]

77. Tsurusawa M, Shimomura Y, Asami K, et al. for the Japanese Childhood Cancer and Leukemia Study Group. Long-term results of the Japanese Childhood Cancer and Leukemia Study Group studies 811, 841, 874 and 911 on childhood acute lymphoblastic leukemia. Leukemia. 2010; 24:335-44. [PubMed: 20016539]

78. Tebbi CK, London WB, Friedman D, et al. Dexrazoxane-associated risk for acute myeloid leukemia/myelodysplastic syndrome and other secondary malignancies in pediatric Hodgkin's disease. J Clin Oncol. 2007; 25:493-500. [PubMed: 17290056]

79. Lipshultz SE, Lipsitz SR, Orav EJ. Dexrazoxane-associated risk for secondary malignancies in pediatric Hodgkin's disease: a claim without compelling evidence. J Clin Oncol. 2007; 25:3179. [PubMed: 17634500]

80. Hellmann K. Dexrazoxane-associated risk for secondary malignancies in pediatric Hodgkin's disease: a claim without evidence. J Clin Oncol. 2007; 25:4689-90. [PubMed: 17925567]

81. Le Delay M-C, Leblanc T, Shamsaldin A, et al. Risk of secondary leukemia after a solid tumor in childhood according to the dose of epidpodophyllotoxins and anthracyclines: a case-control study by the Societe Francaise d'Oncologic Pediatrique. J Clin Oncol. 2003; 21:1074-81. [PubMed: 12637473]

82. Hijiya N, Ness KK, Ribeiro RC, Hudson MM. Acute leukemia as a secondary malignancy in children and adolescents: current findings and issues. Cancer. 2009; 115:23-35. [PubMed: 19072983]

83. Bardi E, Bobok I, Olah AV, Kappelmayer J, Kiss C. Anthracycline antibiotics induce acute renal tubular toxicity in children with cancer. Pathol Oncol Res. 2007; 13:249-53. [PubMed: 17922055]

84. Hu ST, Brandle E, Zbinden G. Inhibition of cardiotoxic, nephrotoxic and neurotoxic effects of doxorubicin by ICRF-159. Pharmacology. 1983; 26:210-20. [PubMed: 6844396]

85. Thompson KL, Rosenzweig BA, Zhang J, et al. Early alterations in heart gene expression profiles associated with doxorubicin toxicity in rats. Cancer Chemother Pharmacol. 2010; 66:304-14.

86. Nysom K, Colan SD, Lipshultz SE. Late cardiotoxicity following anthracycline therapy for childhood cancer. Prog Pediatr Cardiol. 1998; 8:121-38.

87. Sallan SE, Lipshultz SE. Wise up: do not do it without protection! Pediatr Blood Cancer. 2005; 45:872-73. [PubMed: 16206201] 
88. Barry, EV.; Lipshultz, SE.; Sallan, SE. Anthracycline-induced cardiotoxicity: natural history, risk factors, and prevention. In: Govindan, R., editor. American Society of Clinical Oncology 2008 Educational Book. Alexandria: American Society of Clinical Oncology; 2008. p. 448-53.

89. Scully, R.; Lipshultz, SE. Cardiovascular toxicity of antitumor drugs: dimensions of the problem in children. In: Minotti, G., editor. Cardiotoxicity of non-cardiovascular drugs. London: John Wiley \& Sons; 2010. p. 97-126.

90. Rhomberg, W.; Hellmann, K., editors. Experimental and clinical results. 1. London, New York: Springer; 2010. Razoxane and dexrazoxane-two multifunctional agents.

91. Choi HS, Park ES, Kang HJ, et al. Dexrazoxane for preventing anthracycline cardiotoxicity in children with solid tumors. 


\section{Panel: Research in context}

\section{Systematic review}

We have previously published systematic reviews as part of the planning for this trial. ${ }^{33,86}$ We continued to review this during the trial, as have others. ${ }^{18,21,24,87-90}$

\section{Interpretation}

Collectively, the findings of previous trials and the present trial suggest that dexrazoxane use does not adversely affect oncological efficacy in children with high-risk ALL and reduces cardiotoxicity in long-term survivors. We encourage paediatric oncology protocols for children with high-risk ALL containing doxorubicin to use dexrazoxane before doxorubicin dosing, and to do so in the setting of clinical trials in which dexrazoxane's use can be monitored. 


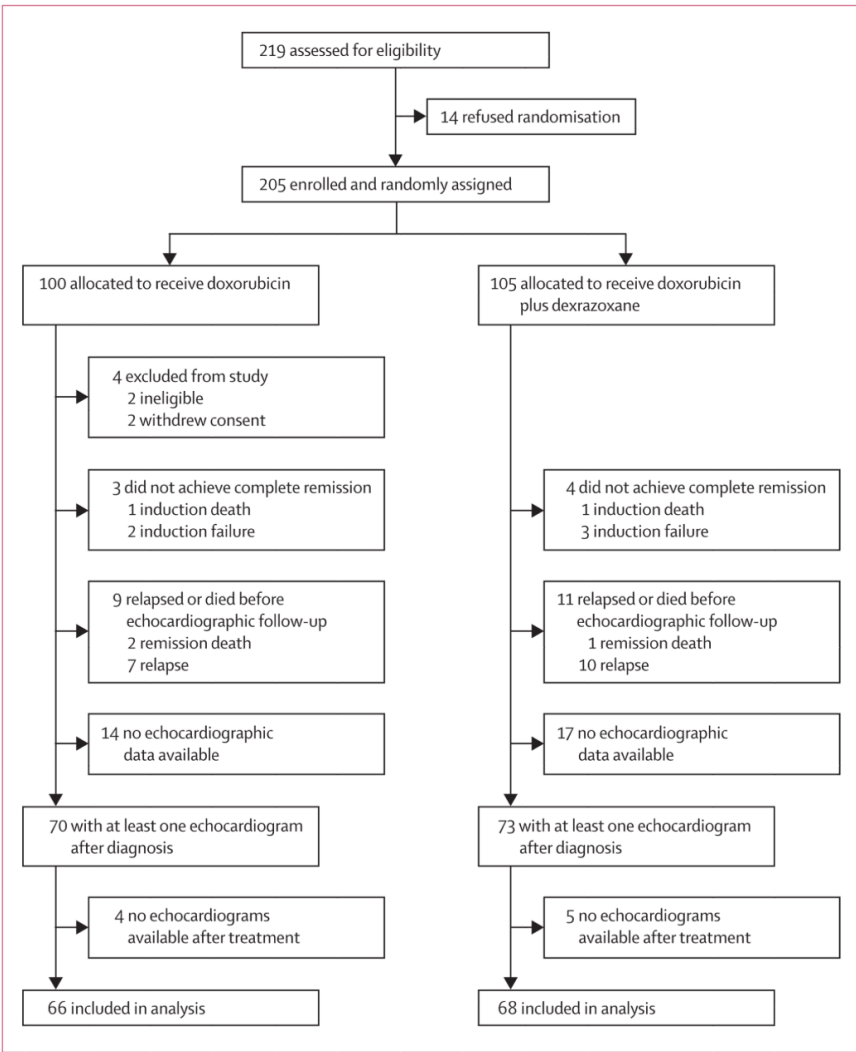

Figure 1.

Trial profile 


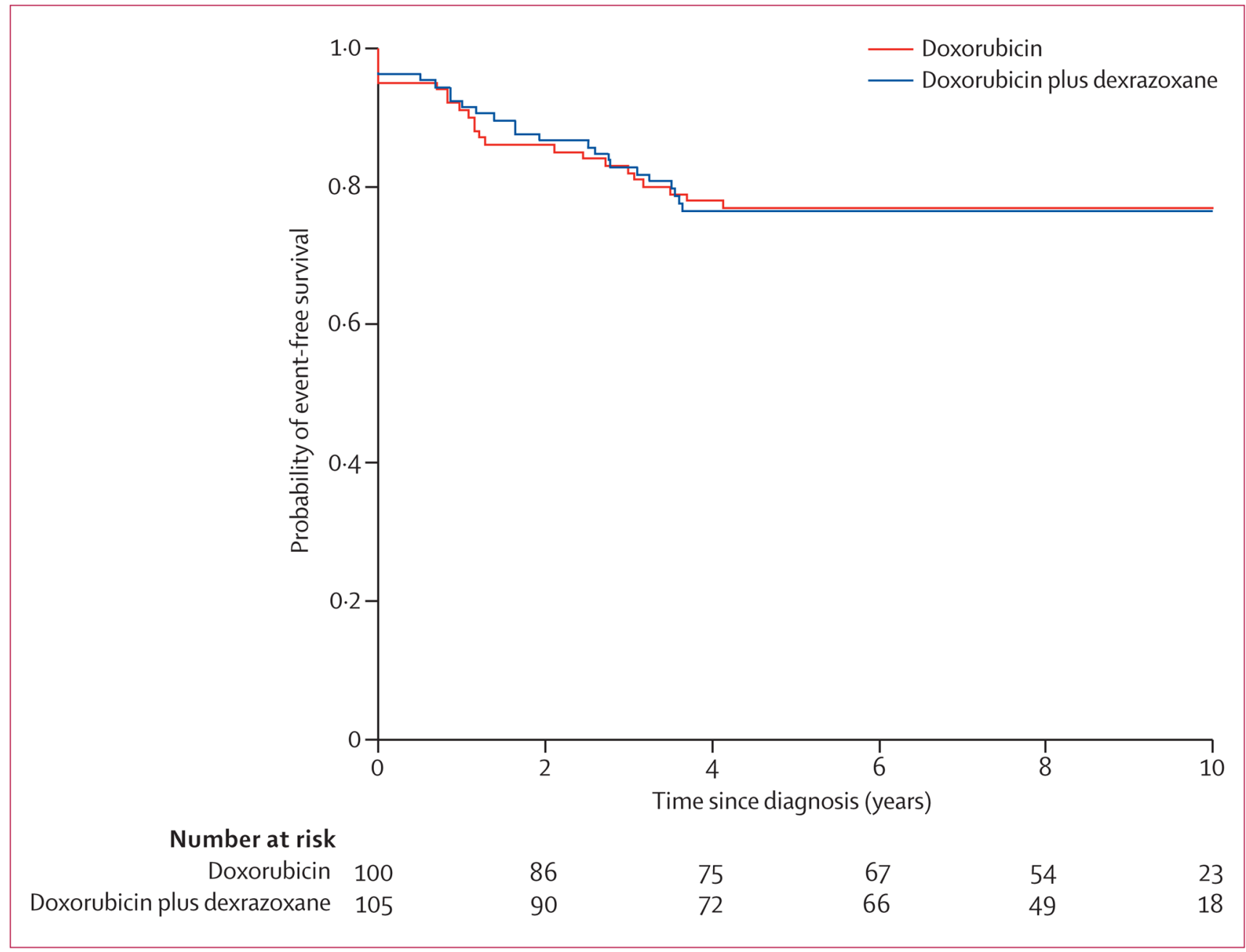

Figure 2. Event-free survival All

patients randomly assigned treatment $(n=205)$ were eligible for assessment of event-free survival, but by convention, events of induction failure and induction death have been recorded at 0 years. 


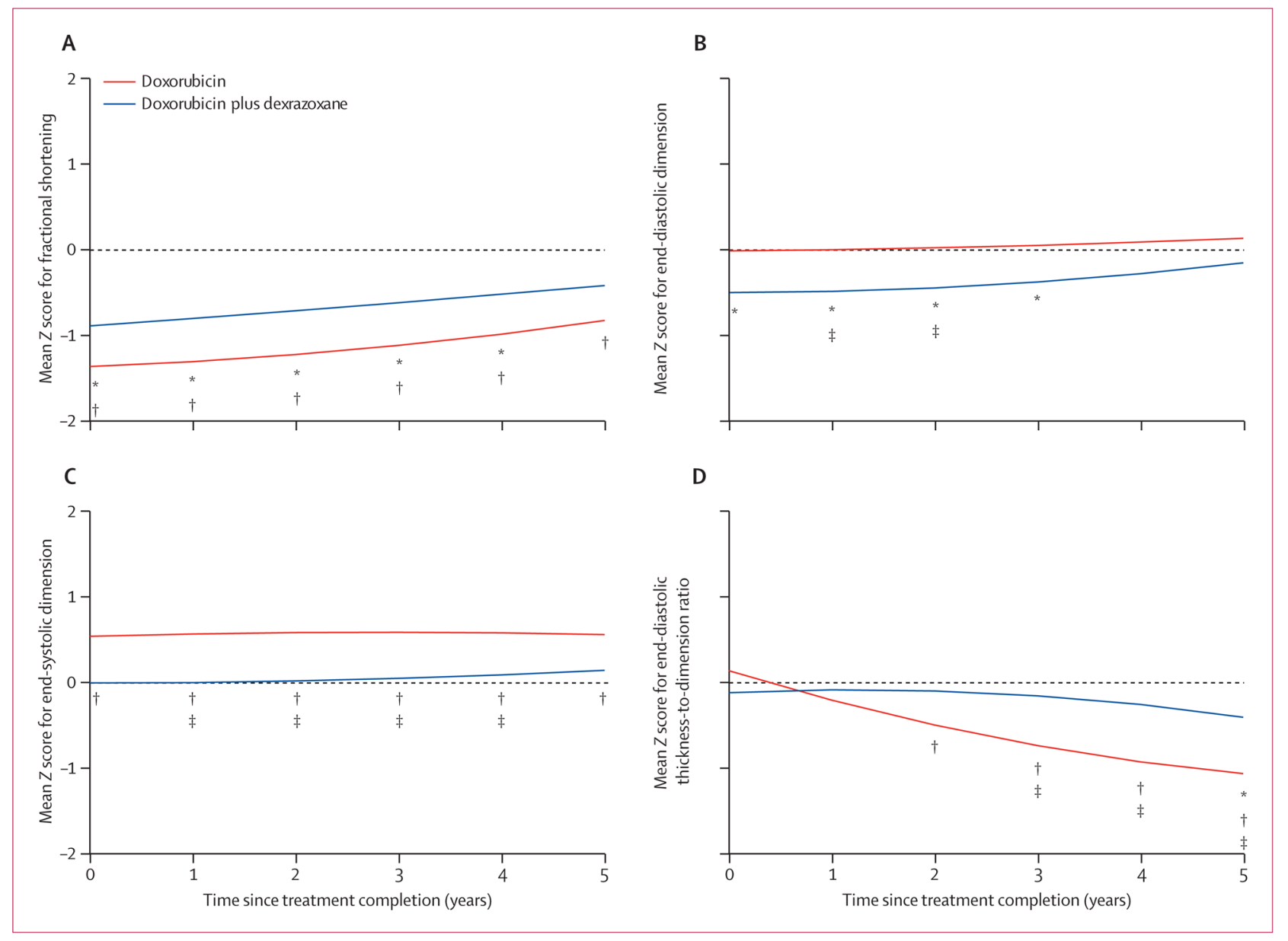

Figure 3. Mean left ventricular echocardiographic $Z$ scores $(n=134)$

Plots are adjusted for age and sex. *p $₫$ ).05 for comparison of the mean $Z$ score of the doxorubicin plus dexrazoxane group with zero. ${ }^{\dagger} \mathrm{p} \$ 0.05$ for comparison of the mean $Z$ score for the doxorubicin group with zero. ${ }^{\star} \mathrm{p} \$ \mathbf{0} 05$ for comparisons of mean $Z$ scores between the doxorubicin and doxorubicin plus dexrazoxane groups. 

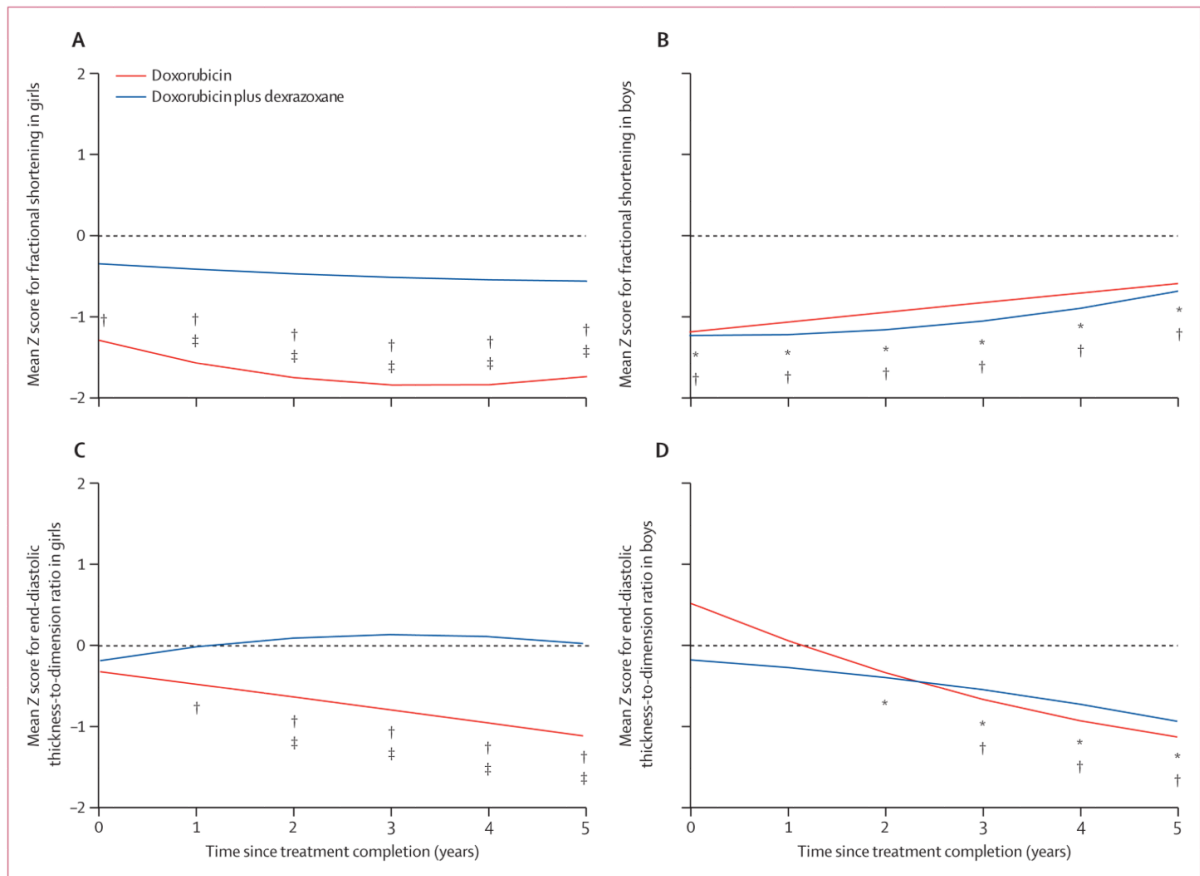

Figure 4. Mean left ventricular echocardiographic $Z$ scores in boys and girls $(n=134)$ Plots are adjusted for age. ${ }^{*} \mathrm{p} \unlhd(05$ for comparison of the mean $Z$ score of the doxorubicin plus dexrazoxane group with zero. ${ }^{\dagger} \mathrm{p} \unlhd$ ). 05 for comparison of the mean $Z$ score for the doxorubicin group with zero. $\left.{ }^{\ddagger} \mathrm{p} \unlhd\right) .05$ for comparisons of mean $Z$ scores between the doxorubicin and doxorubicin plus dexrazoxane groups. 
Table 1

Demographic and clinical characteristics of study participants

\begin{tabular}{|c|c|c|}
\hline & Doxorubicin alone & Doxorubicin plus dexrazoxane \\
\hline \multicolumn{3}{|c|}{ Patients with at least one echocardiogram after diagnosis } \\
\hline Total & 70 & 73 \\
\hline \multicolumn{3}{|l|}{ Sex } \\
\hline Male & $31(44 \%)$ & $29(40 \%)$ \\
\hline Female & $39(56 \%)$ & $44(60 \%)$ \\
\hline \multicolumn{3}{|l|}{ Ethnic origin * } \\
\hline White & $63(90 \%)$ & $62(86 \%)$ \\
\hline Non-white & $7(10 \%)$ & $10(14 \%)$ \\
\hline Mean age at diagnosis (years) & $7 \cdot 8(5 \cdot 5)$ & $7 \cdot 6(5 \cdot 1)$ \\
\hline \multicolumn{3}{|c|}{ Patients with at least one echocardiogram after treatment } \\
\hline Total $^{\dagger}$ & 66 & 68 \\
\hline \multicolumn{3}{|l|}{ Sex } \\
\hline Male & $30(45 \%)$ & $27(40 \%)$ \\
\hline Female & $36(55 \%)$ & $41(60 \%)$ \\
\hline \multicolumn{3}{|l|}{ Ethnic origin ${ }^{t}$} \\
\hline White & $61(92 \%)$ & $58(88 \%)$ \\
\hline Non-white & $5(8 \%)$ & $8(12 \%)$ \\
\hline Mean age at diagnosis (years) & $7 \cdot 9(5 \cdot 4)$ & $7 \cdot 6(4 \cdot 9)$ \\
\hline Cumulative doxorubicin dose $\left(\mathrm{mg} / \mathrm{m}^{2}\right)$ & $300(288-300)$ & $300(300-300)$ \\
\hline Number of echocardiograms per patient & $4 \cdot 0(3 \cdot 0-6 \cdot 0)$ & $4 \cdot 0(2 \cdot 0-7 \cdot 0)$ \\
\hline Echocardiographic follow-up (years) & $5 \cdot 7(2 \cdot 8-7 \cdot 6)$ & $6 \cdot 2(3 \cdot 0-7 \cdot 7)$ \\
\hline \multicolumn{3}{|c|}{ Echocardiograms by time since assignment (years; number of echocardiograms/number of patients) } \\
\hline 0.00 to 1.67 & $65 / 44$ & $70 / 43$ \\
\hline$>1.67$ to 3.33 & $47 / 37$ & $46 / 37$ \\
\hline$>3.33$ to 5.00 & $34 / 31$ & $39 / 34$ \\
\hline$>5 \cdot 00$ & $52 / 38$ & $60 / 41$ \\
\hline
\end{tabular}

Data are number (\%), mean (SD), or median (IQR) unless otherwise indicated.

One child in the doxorubicin plus dexrazoxane group had missing data for ethnic origin.

${ }^{\dagger}$ Children eligible for inclusion in analyses had completed treatment and were in their first continuous complete remission.

Two children in the doxorubicin plus dexrazoxane group had missing data for ethnic origin. 


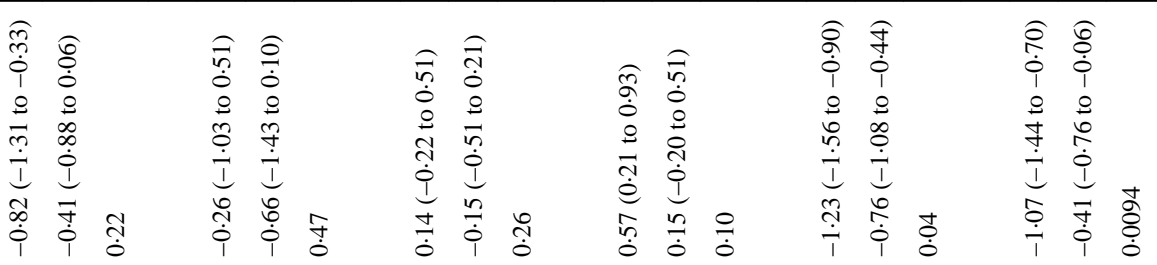

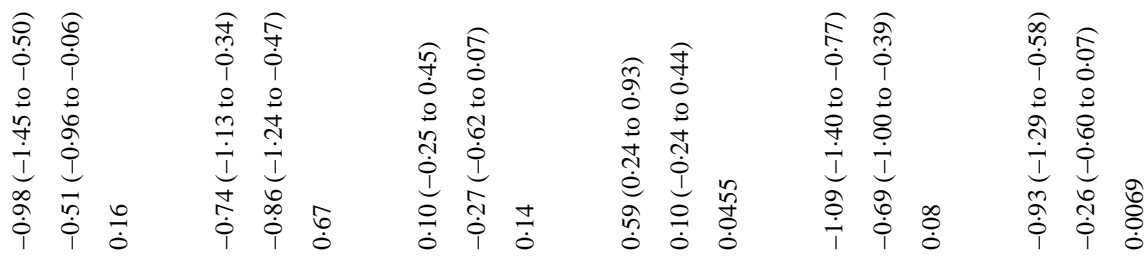

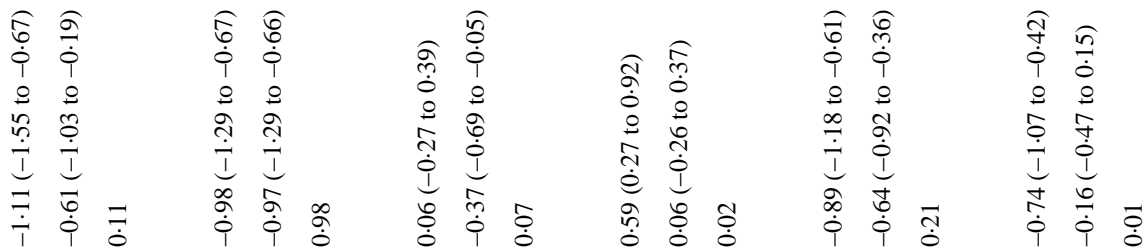

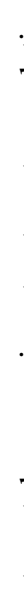

in<smiles>CC1CC1(C)C</smiles>

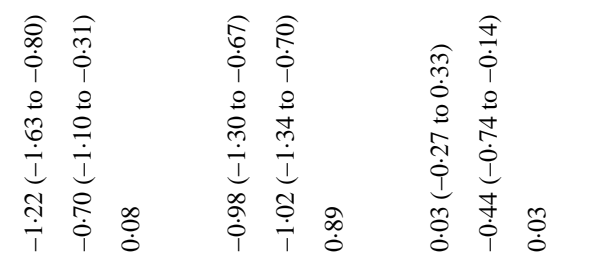

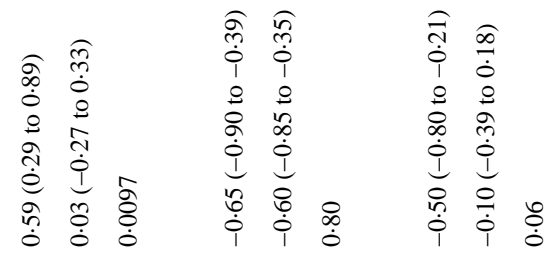

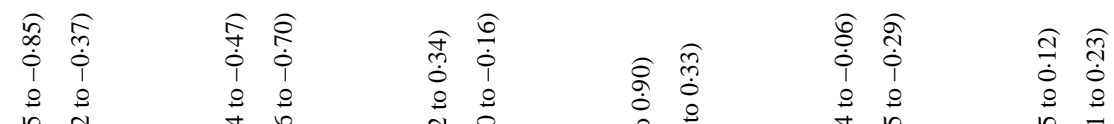

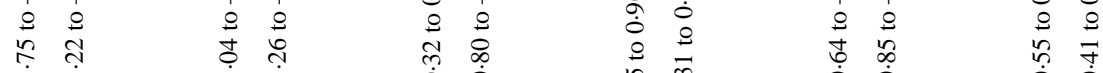

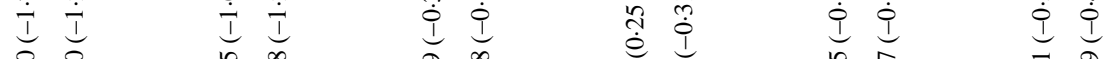

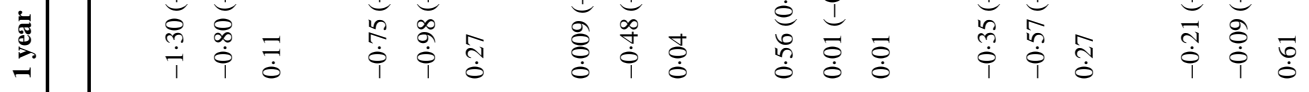

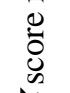

†े

ơ

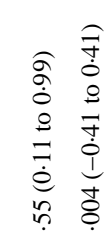

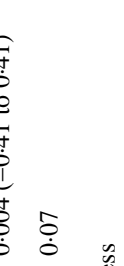

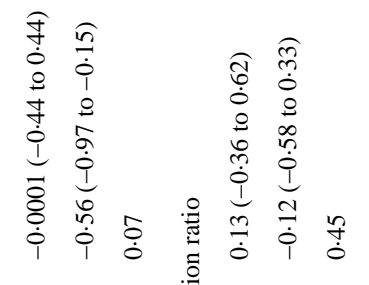




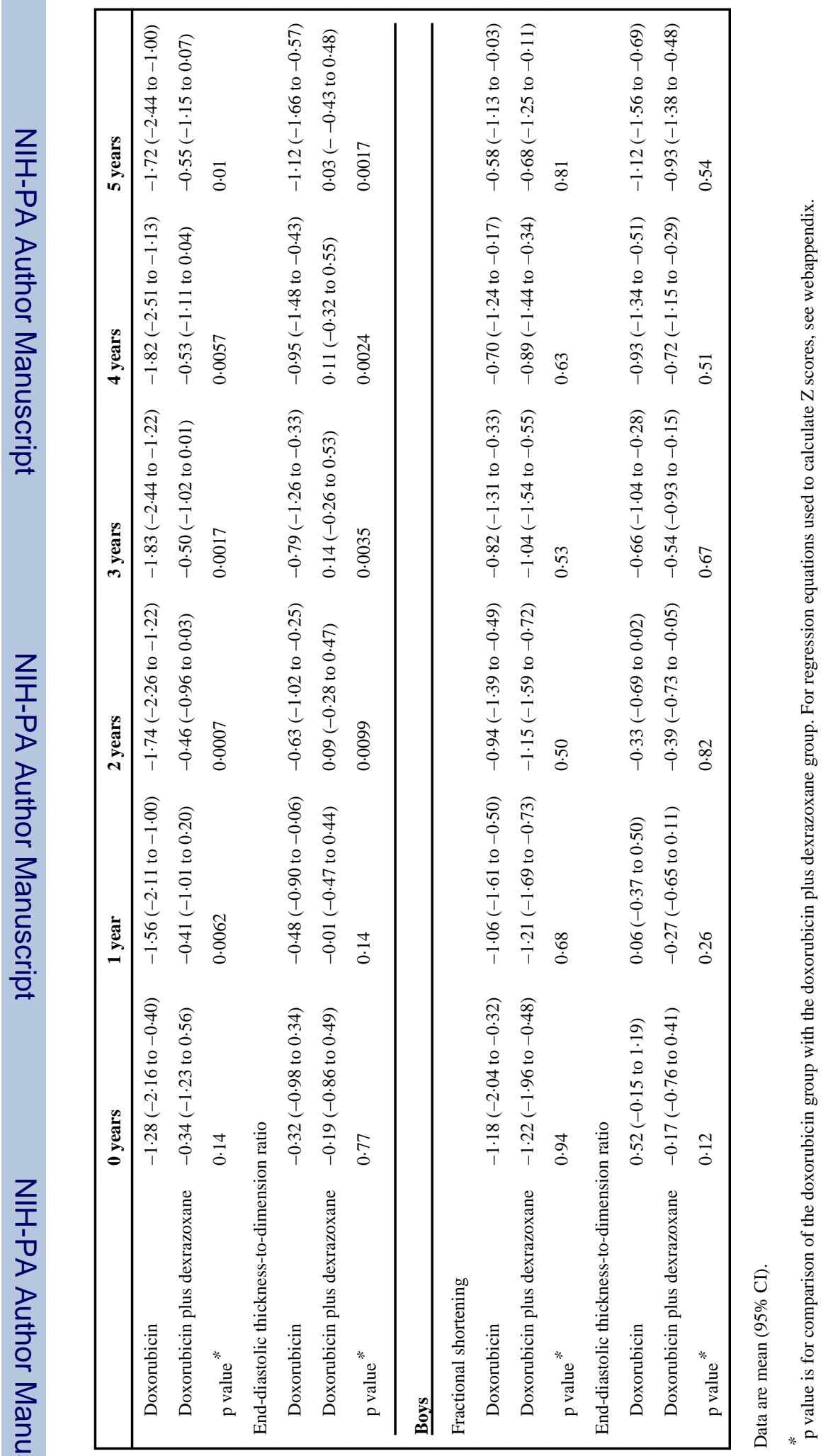




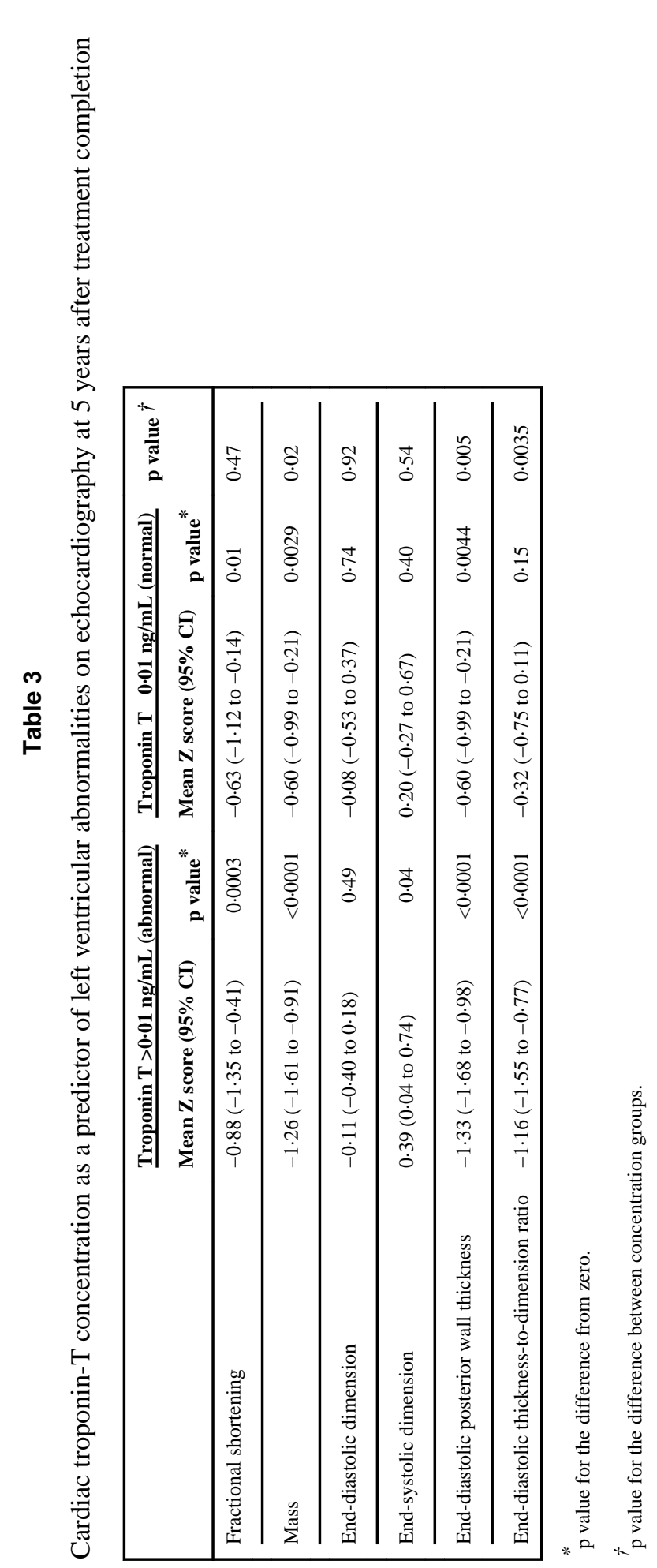

Lancet Oncol. Author manuscript; available in PMC 2013 August 28. 